\title{
Ethnicity, voting and the promises of the independence movement in Mwanza, Tanzania'
}

\author{
Mrisho Mbegu Malipula \\ Department of Languages and Cultures (African Studies), Ghent University
}

\begin{abstract}
This report explores influences of ethnicity on determining voters' choices in Tanzania. It questions the dominant neo-patrimonial and hybrid approaches to African politics, which argue that primordial (traditional) ways of organising politics inform ethnic voting. This study deviates from ethnic structure theorists arguing that outcomes of elections are determined by the ability of ethnic groups to form minimum winning coalitions (MWCs). Instead, it looks at the ideational structure of nationalisation, driven mainly by the promises of the independence movement (PsIM). The movement created an experiential and discursive framework that emphasises depoliticisation of ethnicity, peacefulness and national unity as 'Tanzanian' national values. The frame is intact despite Tanzania's ethnic diversity and liberal socio-economic as well as political reforms it has undergone overtime. The report critically divulges this capacity to build a political organisation encompassing the political leaders, ideals of the independence movement and the people in informing voters' choices.
\end{abstract}

Key words: ethnicity, neo-patrimonialism, hybrid regimes, promises of independence and voting

\section{Introduction and argument}

The present research has come a long way to elicit the influences of ethnicity in informing voters' choices in elections in Tanzania ${ }^{2}$. The overriding literature on ethnicity ${ }^{3}$ and voting in Africa regards ethnicity as a central cleavage in informing voters' choices in elections (Bratton et al., 2011). Such line of thinking suggests that Africans politicise ethnicity ${ }^{4}$

This is the report of PhD research carried out at Ghent University, under the supervision of Koenraad Stroeken.

2 Tanzania is a United Republic formed as the result of a merger between Tanganyika and Zanzibar states in 1964 . The scope of this report is the then Tanganyika.

3 Ethnicity is the inclination of individuals defining themselves and others in terms of their ethnic origins. Ethnicity has a group context that includes individuals belonging to a social group with ethnic traits known to it and others which inform their interactions among themselves and with others. Since in Tanzania such groups are culturally and socially referred to as tribes, Kabila in Swahili, ethnicity in this article is defined in the confines of tribalism.

4 Politicised ethnicity in this report refers to a politically oriented consciousness of ethnic belonging which informs active ethnic identities engagement in political affairs. The engagements entail leaders disproportionate 
and are ethnic voters. The significance of ethnicity on determining electorates' choices indicated lacks differentiation of levels of ethnic salience in Africa. Tanzania for instance, exhibits a striking ethnic plurality with over 120 ethnic groups socially and culturally recognised, but, has a lower salience of ethnicity in voting compared to most African states (Malipula, 2014). In light of the overriding literature, the fact that Tanzania is not being structured on this cleavage despite its ethnic diversity is, so to speak, 'abnormal' for an African state.

Knowledge of the influences of ethnicity on determining voters' choices is mainly limited to ethnic structure, neo-patrimonial and hybrid explanations. The ethnic structure school contends that a country's ethnic structure - the number and size of ethnic groups - can explain the influence of ethnicity in voting (Posner, 2005). As such, countries with few and large ethnic groups are expected to be ethnically politicised as they are endowed with ethnic groups large enough to form minimum winning coalitions (MWCs). These MWCs are said to influence voting because voters expect rewards for being part of a MWC. The contrary is viewed to be true for countries with an array of small ethnic groups which force contestants to reach out to, and win votes from, a myriad of ethnic groups through a national appeal (Weber, 2010). As convincing as the ethnic structure view may be in terms of strategic rationality, the political-ethnographic school questions its validity on grounds of the dynamic and contextual reality of ethnic identities, which a static conceptualisation of ethnic groups and their politicising effect fails to grasp (Malipula, 2014). Against both the ethnic structure argument and its critique, Miguel (2004) suggests that nation-building policies and practices can moderate ethnic politicisation. To Miguel, nation-building can mitigate politicisation of ethnicity, while lack of the same can exacerbate it regardless of the ethnic structure.

The neo-patrimonial and hybrid models are discussed together because they commonly associate salience of ethnicity in voting in Africa with a lack of Legal Rational Institutions (LRIs) and ideals to bar ethnic-based primordial resource distribution (Bratton and Van De Walle, 1997). The difference is that while neo-patrimonialists claim the LRIs do not exist, hybrid proponents recognise that they do, and operate alongside traditional ones. The duality of these institutions in Africa merited the name hybrid regimes (Nyaluke, 2013). However, they contend that the LRIs are dysfunctional, and therefore, primordial tendencies take precedence. As such, African rulers use neo-patrimonial practices like politicising ethnicity to win votes. In this view, Tanzania is expected to be ethnic salient in voting as it has malfunctioning LRIs and strong social and cultural ethnic identities. However, it is not, thus depicting the over-generalised nature of the neo-patrimonial and hybrid explanations of African politics. In this regard, primordial tendencies alone cannot satisfactorily explain the influences of ethnicity. Furthermore, neo-patrimonial and hybrid explanations suffer from their essentialist interpretation of African history and

distribute public resources in favour of their ethnic-mates to register their political support in return. As such, members of other ethnic groups rally against such segregation by voting against the favoured ethnic group(s). 
traditions. This essentialist view fails to appreciate alternative political ideas and structures relevant to Africa (Mustapha, 2002; Pitcher et al., 2009). For instance, against the claim of Africans' primordial tendencies politicising ethnicity, there is sound evidence in terms of elections in Tanzania, (Malipula, 2014; Weber, 2010) as well as in terms of extant ideals and values countering neo-patrimonialism (Pitcher et al., 2009). Therefore, this study through the promises of the independence movement (PsIM) integrates the role of African histories in the analysis of ethnicity and voting.

The PsIM in Africa were born in response to the undemocratic, divisive and exploitative colonial regimes. In essence, they promised the African people all that colonialism had denied them. Generally, the PsIM pledged to Africans that their states will be politically democratic and just, equitably developed and as welfarist as possible, and nationally united and peaceful (Nyaluke, 2013). The PsIM in Tanzania were interpreted into a concrete ujama $a^{6}$ - based policy blueprint called the Arusha Declaration (AD). The AD aimed at building a society in which its members are accorded equal rights and opportunities, coexist peacefully and without being exploited (Hyden, 1980). At its core, the AD meant to enhance national unity and restrict differential acquisition of wealth and shun attendant divisions and conflicts, which could follow growing inequality. Arguably, the $\mathrm{AD}$ thus provided a palliative to ethnic-based disparities that could become politicised and ensue ethnic voting.

The current research has been motivated by the reassessment of the African history school that criticises neo-patrimonialism and hybrid approaches on the influence of ethnicity on voting. On its part, it employs African history informed by colonialism and the resultant PsIM to explain influences of ethnicity on voting in Tanzania. The study endeavoured to present a critique to the neo-patrimonial and hybrid schools and set up an alternative explanation for the continued limited influence of ethnicity in anchoring voting in elections in Tanzania despite political and economic changes that have occurred over time. The alternative approach employed to understand the role of ethnicity in influencing voting that this study suggests rests on the idea of a path-dependent nationalisation framework. The nationalisation frame in question results from the political ideas and aspirations of the independence movement, and the capacity of that movement to build a political organisation encompassing the political leaders, ideals of the independence movement and the people. The study uses the 20ro General Elections (GEs) in Mwanza region as a case study to attest this framework. At its core, the study explores the ramifications of the implementation of the PsIM on influencing voters' choices in Tanzania. 
More specifically, it analyses how and why the implementation of the PsIM (PNU7, EDNR ${ }^{8}$ and peace ${ }^{9}$ impacts the way Tanzanians interact and apply ethnicity in the electoral processes and subsequently vote. Cognisant of the low salience of ethnicity in voting in Tanzania, the study explores peripheral bursts of ethnicity termed politics of origin, being and belonging.

\section{Methodology}

The data employed in this study were garnered from a sum of $6_{5}$ interviews. The interviews were conducted with 48 voters and ro party and government leaders in Mwanza as well as 7 Key Informant Interviews (KIIs) with politicians (3), journalists (3) and one expert of Tanzania's social structure. The Key Informants involved in the study were seasoned politicians having served in Ministerial and high ranked party portfolios and journalists who widely wrote academic papers in the media and/or covered electoral stories. They were meant to provide deeper historical understanding of the interface between ethnicity and voting in Tanzania overtime. I also interviewed 2 party leaders of the most successful parties in the study area CCM - Chama cha Mapinduzi (The Revolutionary Party) and CHADEMA - Chama cha Demokrasia na Maendeleo (Democratic and Progressive Party). Equally, 4 village and 4 street leaders were involved in the sample. The voters included in the study were randomly selected from two districts in Nyamagana and Misungwi. The former represented the urban setting of Mwanza while the latter represented the rural areas. In both districts two wards were randomly selected. From the wards, two villages in each rural ward and two streets in each of the urban wards were selected. Households were randomly selected from lists of the households found in the villages and streets. Interviewees from the households ( 12 from each street or village) making the total number of voters interviewed to be 48 . The study made use of documentary reviews to complement and check the interviews. The data in this study were analysed using structural content analysis and by triangulating data among interviewees and against secondary data. The subsequent part presents a concise abstract of the findings and conclusions of each core issue studied.

\section{PsIM, ethnicity and voters' choices in Tanzania}

The first objective of the study was to explore how the PsIM influenced voting in the 2oro elections in Tanzania. I found that the PsIM informed low salience of ethnicity in the determination of voters' choices in elections. The analysis and discussion of the PsIM and various initiatives undertaken to put them to effect in the area of national unity,

\footnotetext{
Promise of National Unity.

Equitable Distribution of National Resources.

There are two versions of peace. One regards peace as the absence of war and another goes beyond that by including presence of social justice, democracy and reconciliation. However, literature and interviewees' views on ethnicity and voting mostly revolved around the violent aspects of peace and effects thereof. As such, peace in this study is informed by the absence of warfare and massive violence. In this context, Tanzania's peacefulness rests on its lack of civil war or civil disobedience compared to countries like Burundi and Rwanda were genocide occurred, and Kenya with the ethnic-based post-2007 elections, that merited an ICC case.
} 
EDNR and peace have lowered the significance of ethnicity in motivating voters' choices. The analysis indicates that the PsIM are responsible for creating a nationalistic political culture that militated against the salience of ethnicity in motivating voters' choices in elections. This political culture is manifested in Tanzanians' unprecedented pride of their national identity over their ethnic groups' identity, their appreciation of EDNR as well as the value they place on peace when they are encountered with electoral decisions. The culture is clearly evidenced by the frequency with which the interviewees cited the significance of national unity, limited feelings of inter-ethnic mistrust and inter-ethnic discrimination, EDNR informed by the legacies of villagisation ${ }^{\text {to }}$ and nationalisation ${ }^{11}$, and peace. The interviewees considered the culture to be the primary source of national pride and the stumbling block to salience of ethnicity on determining voters' choices in elections. From such background, salience of ethnicity in luring and informing voters' choices in the 2010 elections would have been navigating against the direction of the nationalistic political culture they believe in.

The PsIM proved to be relevant in explaining the influences of ethnicity on voters' choices even after the collapse of the backbone of the PsIM - the Arusha Declaration, and the implementation of liberal economic and political policies from the rg9os to-date. In this regard, I argue that the PsIM and the efforts to realise them have created a frame that informs Tanzanians' rejection to letting ethnicity gain salience on determining voters' choices in elections regardless of the political and /or ideological changes it has underwent over-time. Such situation questions the claim advanced by the neo-patrimonial and hybrid schools that African states including Tanzanians lack common political history and convictions that can lower salience of ethnicity in elections. And therefore, they are doomed to embrace traditional tendencies (tribalist client-patron relations) which among other things breed salience of ethnicity on determining voters' choices. The relevance of the content of the PsIM in lowering ethnic salience confirms that Africans have a shared history and ideals that can explain varied developments. As such, I criticise the neo-patrimonial and hybrid schools of being reluctant to appreciate alternative political ideas, agencies and structures to their own, to explain African politics, including the influence of ethnicity on determining voters' choices.

Explaining the influences of ethnicity on determining voters' choices

After pointing out how the PsIM and attempts made to realise them have informed low salience of ethnicity in the 2010 elections, in this section we present and discuss the reasons as to why this is the case. Factors identified by my interviewees and discussed are the national building frame, the role of Swahili in ethnic integration and peaceful co-existence, generational denunciation of the use of ethnicity in soliciting political sup-

Io Villagisation entailed removing people from scattered areas to live together in newly created villages to ensure collective production and the sharing of public goods including social amenities.

II Nationalisation of the major means of the economy refers to putting the previously privately-owned properties owned by foreigners in the hands of the Tanzanians through their government and sharing its produce. 
port, Mwalimu ${ }^{12}$ Nyerere's charismatic and symbolic leadership in the nation-building project and legal restrictions of the use of ethnicity in political canvassing.

\section{The nation building frame}

It was revealed that low salience of ethnicity in voting has been influenced by the negative projection of ethnicity in the country's development endeavours. As a starting point, Tanzania framed enemies of development in war terms, thus making the requisites for winning the war - national unity and peace - do and die issues. This war imagery provided Tanzanians with the motivation and conviction necessary for channelling their ferociousness against the enemies of development and guarantee that the requisite for success - national unity and peace - are highly respected. The respect for national unity and peace contributed to diffusing the significance of ethnicity on determining voters' choices. This argument is informed by the fact that political canvassing and voting along ethnic lines would breed disunity and violent conflicts among competing ethnic groups which would affect the victory in the war against the enemies of development whose success is essential for Tanzanians' progress. In this way, Tanzania's framing of its development efforts as a war helped to unify its people toward denouncing ethnic salience in voting and beyond. Likewise, the negative impacts of ethnic polarisation on development endeavours in countries like Burundi and Rwanda added impetus in influencing Tanzanians disinterest in ethnic voting. The views above questions the neo-patrimonial thesis that Africans are short of political ideas and convictions that can make them lower the influence of ethnicity on informing voters' choices.

\section{The role of Swahili in ethnic integration and peaceful co-existence}

The study also revealed that the PsIM, particularly their national integration endeavour, have benefitted a lot from the use of Swahili as a national language. It has been established that almost all of the multi-ethnic integrative initiatives would have been seriously crippled without Tanzanians sharing a common lingua franca. Multi-ethnic communications and nationalist messages were made possible by Swahili. And Tanzanians ethnic groups loose a valuable tool for furthering ethnic identity that could be used for political visibility. Inferably, Swahili has facilitated the national unity and peace components of the PsIM by reducing lingual informed parochial identities and ethnic miscommunication. Correspondingly, Swahili enhanced multi-ethnic communication for the attainment of the nation-building policies that contributed in informing voters to harbour feelings of national identity over ethnic ones. The feelings diffused the significance of ethnicity on determining voters' choices. The choice of Swahili as a national language, its role in enhancing national unity and peace promised by the PsIM and subsequently informing low salience of ethnicity in voting questions the neo-patrimonial explanations of ethnicity and voting. I argue that the preference for national language and identity over vernacular and ethnic ones respectively, renders the neo-patrimonial thinking redundant.

12 Mwalimu is a Swahili word that literally means Teacher. Julius Nyerere was widely referred to as Mwalimu by his fellow countrymen. He was a teacher by learning and practice who chanced to teach among others, the third President of Tanzania, Benjamin William Mkapa. 
More important, the nationalist initiative of using Swahili from the independence movement to-date to facilitate a nationally integrated polity indicates that the neo-patrimonial claim that Africans lack political thoughts, history, and cultures to disentangle from the web of ethnic salience is irrelevant in Tanzania.

\section{Generational denunciation of the use of ethnicity in soliciting political support}

Interviews have established that a series of concerted efforts by the political establishment and other stakeholders to sustainably denounce the significance of ethnicity in anchoring voters' choices from independence to-date. The denunciation was made possible by extensive civic education. The civic education endeavoured to make sure that the post-independent movement generation subscribed to the idea of denouncing ethnicity in motivating voters and spread the same to generations to come. This was facilitated by, among other things, the use of Swahili and the implementation of the comprehensive nation-building policies. The sustained anti-ethnic civic education and the nation-building efforts point to an opposite direction of the neo-patrimonial argument that Africans lack the ideals and zeal to lower the salience of ethnicity in voting. In the main, it quashes the conception that Africans are fond of traditional ethnic-based patronage tendencies which exacerbate ethnic polarisation and voting. Interviews have established that the PsIM have inspired extensive denunciation of ethnicity and the implementation of the PsIM further reinforced this. In this vein, I argue that the marriage between the nation-building policies argued in the first objective above, and continuous transfer of anti-ethnic education have sunk into people's minds to the level that an opposite discourse is hard to be bought. Generational denunciation of the use of ethnicity is further corroborated by Mwalimu's charismatic and symbolic leadership in the nation-building policy.

\section{Mwalimu Nyerere's charismatic and symbolic leadership in the nation building project}

Political scientists tend to undermine the indispensability of individual agency in the realisation of outcomes of modern organisations. However, the frequency of mentioning Mwalimu in the fight against ethnic salience in voting indicates that organisations can benefit from charismatic individuals. Mwalimu Nyerere's anti-ethnic views and deeds about rejecting ethnic voting have contributed towards making Tanzanians consider ethnic salience in motivating voters' choices unpatriotic and un-Tanzanian. The fact that Mwalimu personally wrote the $\mathrm{AD}$, that his anti-ethnic views have been massively projected in the media because he was at the epitome of the nation-building efforts, that his successors sustained his nation-building crusade and Tanzanians supported the ideas over-time, renders the institutional mantra questionable. I argue that political actors informed by Mwalimu's anti-ethnic salient opinions and deeds, and the adverse impacts of ethnic conflicts in other African countries, contributed in making Tanzanians choose to amplify an ethnically inclusive peaceful national ethos. 


\section{Legal restrictions of the use of ethnicity in political canvassing}

The study also established that legal restrictions on the application of ethnicity in political canvassing, particularly the restriction on the use of vernaculars in campaigning for office, have had a contribution in lowering the salience of ethnicity on determining voters' choices. However, the legislation benefitted from the anti-ethnic culture informed by the PsIM. This view rests on the fact that the political culture prohibits the use of ethnicity in seeking political office. In fact, ethnic salience in voting is considered as a taboo that would destroy national integration, peace, tranquillity and development that most Tanzanians do not want to miss. The fact that there are laws prohibiting the use of ethnicity and LRIs supervising them, questions the relevance of the neo-patrimonial view that the African state lacks legislations and LRIs to stamp ethnic salience in politics. The efficacy of the laws in terms of actual use could not be established. However, I argue that the hypothetical restrictions coupled with the other conclusions made, point towards explaining the low salience of ethnicity on determining voters' choices.

Broadly speaking, the conclusions made under this objective express the complexity and interrelated explanations of sustained low salience of ethnicity on determining voters' choices in Tanzania. In other words, the demarcation between the conclusions made are not water tight, They overlap and, therefore, can well explain the low salience of ethnicity if eclectically and/or complementarily treated. In this sense, all of the factors should be considered as they relate to the PsIM in the context of the electoral politics, actors and structures to explain the way ethnicity motivates voting in Tanzania.

\section{Influences of candidates' origin, being and belonging on voting}

Data garnered from interviews indicate that the importance of origin in terms of being native and the use of Kisukuma - the local language of the research area - in mobilising political support, have been proven to be nominal in the 20 ro elections. The low significance of being a native in luring voters is highly associated with the strong nationalist feeling and the quest for candidates who are trustworthy and able to solve people's problems. Interestingly, candidate's origin was only viewed imperative in judging the trustworthiness and ability of candidates to deliver public goods. In this context, origin is important only if, and when, the candidate is considered to be trustworthy and able to deliver public goods to the community he or she vies to lead. In this regard, the voters have been proven to be moved more by rational and meritocratic calculations of benefitting from able candidates than aspirants originating from the area of contest.

With regard to the ethnic use of Kisukuma there were no convincing facts to establish patterns that are strong enough to suggest its significance in the 20ro elections. This position is anchored on the fact that no evidence pointed to the fact that the language was dominantly used in the formal campaigns, neither did political parties rush to coopt Sukuma speakers to lead their parties or to have only Sukuma speakers contest in the 2010 elections. In the study area and beyond, there are numerous cases where nonSukuma speakers won in the elections against prominent Sukuma speakers or contenders as the Illemela, Kwimba and Geita parliamentary results indicate. The limited use of 
Kisukuma as a tool of ethnic identity in the election questions the claim made by the neopatrimonial theorists that Africans are traditionalists and prefer traditional over modern things. This is because the language widely used in the elections was Swahili which has no traditional dominance of any ethnic group in Tanzania. Kisukuma was recognised in the social settings and traditions, but not in elections. This is due to the strong conviction towards national unity and peace that can be endangered by linguistically-propelled ethnic divisions.

Based on the findings on the politics of origin, being and belonging, it can be said that the Sukuma's numerical dominance and identity provides no guarantee to win political office in Mwanza. The key to political office revolves around being felt to belong to Mwanza and the ability to discharge the demands of public office. Such rational voting practices question the ethnic salient and ethnic-based patronage theses central to neopatrimonial explanations of voting in Africa.

\section{Concluding remarks}

This research rejects the neo-patrimonial and hybrid theses (the main theories used to explain influences of ethnicity on determining voters' choices in African polities) as inadequate tools for understanding the influences of ethnicity on determining voters' choices in Tanzania. This study proposes an alternative framework which draws among others on Mustapha's (2002) idea of political community. According to Mustapha do and don'ts of a political community, people are chiefly informed by ideals deduced from common history and political thoughts entrenched within the political community in question. For the Tanzanian case, its political community is informed by a nationalist political culture embedded in the PsIM. These promises meant to enhance national unity, EDNR and peace which militate against salience of ethnicity on determining voters' choices. This conclusion contradicts the neo-patrimonial theoretical perspectives that claim that the influence of ethnicity on determining voters' choices in Africa is explained in light of Africans' preference to traditional primordial and paternalistic tendencies. Such tendencies are said to give impetus to ethnic salience in politics, personal rule and ethnically-based patronage in the distribution of public resources. As a result, such tendencies breed ethnic voting. Since the current study could hardly find salience of the neopatrimonial suppositions, I consider the theory to be over-generalist in explaining the influences of ethnicity in informing voting in Africa. Such over-generalisation makes the neo-patrimonialism unappreciative of alternative political ideas relevant in explaining the role of ethnicity in influencing voters' choices in Tanzania. This is because it shuns away from analysing the ideals entrenched in its ethno-political history and electoral practices which deviate from the primordial and paternalistic explanations.

This study argues that the alternative framework of ideas can be found in the name of the PsIM that usefully explain the influences of ethnicity on determining voters' choices emanating from the nationalist anti-colonial movement. At its core, this movement promised Tanzanians that their polity will be nationally unified, equitably developed and peaceful - issues that are against salience of ethnicity in political competition (Wimmer, 1997). 
These ideas formed the political community amongst Tanzanians during the struggle for independence and created a political contract between Tanzanian leaders and peoples. The PsIM informed the do and don'ts both during the struggle for independence and in independent Tanzania. This is a significant contradiction of the neo-patrimonial theorists' argument as the study has established values and ideas embedded in the PsIM and struggles for independence that have the capacity to provide an association between state and society in informing low salience of ethnicity in motivating voters' choices.

\section{References}

Bratton, M., Bhavnani, R and Chen, T. (2011). "Voting Intentions in Africa: Ethnic, Economic or Partisan?" in Michael Bratton, ed., Voting and Democratic Citizenship in Africa. Boulder, Colo.: Lynne Reinner Publishers.

Bratton, M. and Van de Walle, N. (1997). Democratic Experiments in Africa: Regime Transitions in Comparative Perspective, Cambridge: Cambridge University Press.

Hyden, G. (1980). Beyond Ujamaa in Tanzania: Underdevelopment and an Uncaptured Peasantry. London: Heinemann.

Lofchie, M. (2013). "The Policy Roots of Civic Peace in Tanzania”, in Ascher. W, and Mirovitskaya, N. (eds.) The Economic Roots of Conflict and Cooperation in Africa, New York: Palgrave Macmillan.

Malipula, M. (2014). "Depoliticised Ethnicity in Tanzania: A Structural and Historical Narrative", Afrika Focus, 27(2) pp. 49-70.

Mamdani, M. (2013). "Nation State-Nyerere's Legacy", Mail and Guardian, Friday, 15 March 2013.

Miguel, E. (2004). "Tribe or Nation? Nation Building and Public Goods in Kenya versus Tanzania", World Politics, 6(3), pp. 327-362.

Mustapha, $\mathrm{R}$ (2002). Intra-state challenges to the nation-state project in Africa, Report of the 2002 CODESRIA Governance Institute.

Nyaluke, D. (2013). Explaining the Basis of African Regime Legitimacy, Democracy and Polity Dominance: The Case of Tanzania, PhD Thesis, Dublin City University.

Pitcher, A., Moran, M. and Johnston, M. (2009). "Rethinking Patrimonialism and Neopatrimonialism in Africa", African Studies Review, Volume 52(1), pp. 125-156.

Posner, D. (2005). Institutions and Ethnic Politics in Africa, New York: Cambridge University Press.

Van de Walle, N. (2003). "Presidentialism and Clientelism in Africa's emerging Party Systems", Journal of Modern African Studies, 4I (2), pp. 297-32I.

Weber, A. (2010). Ethnic Diversity, Clientelistic Resource Distribution, and Politicisation: The Impact of Ethnicity on Education in Africa, a PhD Thesis University of Zurich, Switzerland.

Wimmer, A. (1997). "Who owns the state? Understanding Conflict in Post-colonial Societies", Nations and Nationalism, 3 (4), pp.63i-666. 